\title{
Hayatın Anlamını Semboller Üzerinden Okumak: Dünyanın Boğulmuş En Güzel Adamı
}

\author{
Reading the Meaning of Life Through Symbols: \\ The Handsomest Drowned Man in the World
}

Burcu Tekin*

\begin{abstract}
Özet
İnsanoğlu yaşadığı zaman dilimi boyunca hem ruhsal hem de fiziksel bağlamda deneyimlediği olaylar vasıtasıyla hayatını anlamlandırmaya çalışır. İnsanın kendi yolunu belirleyebilmesi ve hayatın anlamını keşfetmesi uzun ve zorlu bir yolculuktur. Eserler insanın algısının gelişmesini ve olaylara farklı açılardan bakmasını sağlar. Farklı bakış açısı geliştirmenin alternatif yollarından biri de sembollerin yorumlanmasıdır. Eserlerde geçen sembollerin farklı kaynaklar yardımıyla keşfi şüphesiz okurun hayatına anlam kazandıran ve okurun yüksek bir bilince ulaşmasını sağlayan önemli bir düşünsel egzersizdir. Bu çalışma Latin Amerika'da Büyülü Gerçekçilik akımının öncülerinden ve dünya edebiyatının önemli kalemlerinden Gabriel García Márquez’in Dünyanın Boğulmuş En Güzel Adamı adlı öyküsünde hayatın anlamının semboller üzerinden yorumlanmasının aktarılmasından oluşmaktadır. Öyküde Karayipler'de bir köyün deniz kıyısında boğulmuş bir adamın bulunmasıyla süregelen olaylar anlatılmaktadır. Deniz kıyısında köyün çocukları tarafından bulunan ve köyün
\end{abstract}

* Dr. Öğr.Gör. Tobb Ekonomi ve Teknoloji Üniversitesi, Yabancı Diller Bölümü. E mail: burcutekin82@ gmail.com 
kadınları tarafından adı Esteban koyulan bu ölünün hayata dair hiçbir amacı bulunmayan köyü nasıl canlandırdığı ve köyde yaşanan değişimin sonuçları değerlendirilmiştir. Sembol kavramının anlamı, önemi ve kullanım şekilleri genel hatlarıyla verilmiştir. Sembol, edebiyat ve mitoloji arasındaki etkileşime dikkat çekilmiş ve bu temellendirmenin sonrasında öyküde tespit edilen sembollerin hayatın anlamına ilişkin etkileşimi sunulmaya çalışılmıştır.

Anahtar sözcükler: Gabriel García Márquez, Latin Amerika edebiyatı, sembol, hayatın anlamı

\begin{abstract}
During the course of their life span, people try to give life meaning through experiences gained both in spiritual and physical contexts. Defining one's own path and discovering the meaning of one's life can be characterized as a long and challenging journey. Literary works help people develop their perception and look at things from a different perspective. An alternative way to develop different perspectives is symbols. The discovery of the symbols within works thanks to various sources is certainly an intellectual exercise which makes life more meaningful and help develop a higher awareness. This study analyzes the interpretations of the meaning of life through symbols in the story The Handsomest Drowned Man in the World by Gabriel García Márquez, leading author of Magical Realism in Latin America and one of the most significant authors of world literature. The story covers the events after a drowned man is found on the beach of a Caribbean village. This study analyzes how a dead body found on the beach by children and named Esteban by the women in the village revived the village which was once aimless as well as interpreting the results of the change experienced in the village. The study explores the meaning of the concept of symbol, its importance and usage in general terms. The interaction between symbol, literature and mythology is pointed out. Following this grounding, the study presents the symbols found in the story and their relation to the meaning of life.
\end{abstract}

Keywords: Gabriel García Márquez, Latin American literature, symbol, meaning of the life

\title{
Giriş
}

İnsanoğlu cevaplarını bulamadığı sorularla karşılaştığında ve anlam karmaşasına düştügüünde nasıl davranır? Duygularıyla yüzleşmeye ve kendini keşfetmeye cesareti var mıdır? Kendini gerçekleştirmek adına içindeki potansiyel gücün ortaya çıkmasını sağlayabilecek sembolleri fark edecek ve dönüşümü için gerekli adımları atabilecek midir? Genellikle insanlar yaşamlarında bu ve bunun gibi ucu açık sorularla karşılaştıklarında olumlu veya olumsuz tepkileri varlıklarını sorgulamaya yöneliktir. Hayatın anlamını, 
amacını ve varoluş sebebini kendi bakış açılarıyla akıllarında konumlandırmaya çalışırlar. Çeşitli deneyimlerden oluşan bu çıkarımlar, insanın hayatına yön verebilmesi ve sonsuz evren içinde kendi değerinin önemini kavrayabilmesi açısından yol gösterici bir rehberdir.

Frankl (2016) hayatın anlamını ve insanın kendi değerini kavrayabilmesini şu şekilde değerlendirir: "İnsanın hayatın anlamı sorusuna bir şey yaparak, bir faaliyetle, yarattığımız yapıtla ya da ortaya koyduğumuz bir eylemle, somut hayat şartları içinde cevap verebiliriz. (...) Eylem çemberinin çapının büyüklüğü değildir belirleyici olan; daha çok çemberin içinin doldurulup doldurulmadığıdır, bir hayatın gerçekleştirilip gerçekleştirmediğidir" (s. 55). İnsan yaşamında çapını değil içini (ruhunu) doldurmalıdır. Adler (2016) ise anlam arayışına dair düşüncesini şu şekilde dile getirir:

"Kişiliğimizi boşlukta, başkaları için yaratıcı işler yapmak gibi bir amaçtan yoksun geliştirebileceğimize inanmamız, bizi olsa olsa zorba ve çekilmez biri yapar. Yaşamın gerçek anlamının başkaları için yararlı işler yapmak olduğu sonucuna varmamızı sağlayan bir diğer ipucu daha bulunmaktadır. Atalarımızdan devraldığımız mirasa dönüp baktığımızda ne görüyoruz? Kendileriyle gitmemiş tek şey, onların insanlık için yaptıkları yaratıcı çalışmalardır" (s. 15).

Her anlamda hareketsizlik insanda boşluk hissini oluşturur. Amaçsızlık, insanın hayata dair izlerini yok eder, yaşam enerjisini çeker ve yaratıcılığını öldürür. Bu noktada edebiyat ve nitelikli edebi eserin gücü okuyucuyu hayata bağlar çünkü "malzemesi dil, kaynağı yaşantılar ve hayal gücü olan bir yaratıcılık, başka deyişle bir sanat dalı" (Aytaç, 2003, s. 9) olan edebiyat insan hayatına dair izlerin yorumlanabileceği anlam ve varoluş sürecinin değerlendirilebileceği önemli bir alandır. Edebiyatın ilişkili olduğu eserin ve yazarın gücü yadsınmamalıdır. Düş gücü ve cesaretle konfor alanının ötesinin keşfedilmesini sağlayan eserler bireyin kendisiyle bitmek bilmeyen savaşında panzehir görevini üstlenmektedir. Hayatın anlamına dair düşüncelerin şekillenmesinde çeşitli ve göreceli yorumları da içinde barındırırlar. Okur, eserde geçen karakterleri, olayları tek bir eksen üzerinden değerlendirmez, farklılıkları çeşitli kurgular ve semboller vasıtasıyla deneyimler (Manguel, 2017). Varlığının amacını sorgulayan okur ve eser arasındaki etkileşim, evrende tek bir gerçeğin veya tek bir doğrunun olmadığını gösterir niteliktedir. Bucay'a göre (2010) "kendimizi tanımak istiyorsak cesaretle kendimize bakmamız gerekir, bir süre kendimizi kaybetme riskini göze alarak neysek o olmaya karar vermemiz gerekir" (s. 16). Bireyin gelişimi ve hayata dair çekirdek inancının oluşması için kendini tanıması, kendisinin farkına varması, korkularıyla yüzleşmesi ve ne istediğini objektif bir şekilde yorumlayabilmelidir. Ancak insanın belleğinde yer edinen toplumsal normların da etkisiyle bu süreç yaşam içinde zorlu bir dönem olarak değerlendirilebilir. $\mathrm{Bu}$ dönemin atlatılmasında kültürel, evrensel ve mitolojik gibi çeşitli sembollerin yardımıyla yaşamsal bir bilinç geliştirmek ve bu gelişim sürecinde bir yansıtma aracı olarak edebiyatı kullanmak, insanın olumlu veya olumsuz bir olay karşısında hissettiklerini ifade edebilmesindeki netlik bakımından yumuşak bir geçiş sağlar. Hayattaki anlam arayışı 
edebiyat etkileşimi çerçevesinde incelendiğinde, eserler okura kendini tanıması için çeşitli firsatlar sunar. Karakterlerin eserdeki gelişimini gören okur bu durumdan mütevellit kendi içine bakmayı öğrenir, kendisiyle yüzleşir ve eserde geçen çeşitli semboller yard1mıyla hayatın anlamına ve amacına ilişkin kendisi için uygun bir bakış açısı oluşturabilir.

Bu çalışmada dünya edebiyatının önemli isimlerinden ve Latin Amerika'da Büyülü Gerçekçilik akımının öncülerinden Gabriel García Márquez'in Dünyanın Boğulmuş En Güzel Adamı adlı öyküsünde hayatın anlamı üzerinden sembollerin değerlendirilmesi amaçlanmıştır. García Márquez alışılmışın dışında yarattı̆̆ 1 evrenler, olay örgüleri ve karakterleriyle edebi dünyada özgün bir yere sahiptir. Yazar bahsi geçen öyküde düş ve gerçeği bir arada sunmuş, kaosun içinde kurguladığı olağan denge sayesinde okurun dikkatini çekmeyi başarmıştır. Çalışmanın daha anlaşılabilir olması açısından öncelikle genel hatlarıyla sembol kavramına ilişkin tanımların sunulması hedeflenmiştir. Öykü incelemesinde ise sembol kavramının öyküden alınan örneklerle bireyin kendini keşfediş sürecine etkisinin detaylı bir şekilde ele alınması planlanmaktadır.

\section{Genel hatlarılya sembol kavramının değerlendirilmesi}

Birçok eleştirmen, şair, yazar, filozof ve bilim insanı sembol kavramını farklı kuramlarla tanımlamıșlardır. Bu nedenle sembol kavramına ilișkin açıklamalar değerlendirildiğinde doğal olarak kavramın çeşitli şekillerde yorumlanabilirliği konusu gündeme gelir. Fromm (2015) sembol tanımını şu şekilde yorumlar:

"Sembolün tanımı, 'çoğunlukla başka bir şeyin yerinde duran, onun yerini alan, onu temsil eden' olarak yapılmaktadır. Bu haliyle bu tanımı pek anlayamayız. Fakat beş duyumuzu da bazı sembollerle temsil edebileceğimizi düşünür ve bu sembolleri inceleyecek olursak, konu biraz daha ilginçleşecektir. Bunu yapmak için, sözü edilen bu sembollerin bir tecrübenin, bir duygunun ya da bir düşüncenin yerine geçtiğini varsaymamız gerekecektir. Böyle bir sembol, benliğimizin dışını yansıtmaktadır. Sembolize ettiği şey ise içimizde saklıdır" (s. 28).

Jung (2016) sembol kavramına şu şekilde açıklık getirir: "Bizim sembol dediğimiz şey ise günlük hayatta aşina olabileceğimiz, ancak bilinen ve açık anlamına ek olarak belirli bir yan anlama da sahip olan bir terim, isim hatta bir resimdir. Sembol üstü kapal1, karışık bilinmeyen veya bizden gizli bir şeyleri ima eder" (s. 16).

Frye'ın (2015) edebi metinlerde sembol kavramın değerlendirilmesi konusundaki görüşü ise şu şekildedir: "Ne zaman bir şey okusak, ilgimizin aynı anda iki yöne doğru hareket ettiğini görürüz. İlk yön dışa doğrudur ya da merkezkaçtır; şeylerin anlamlarına ya da pratikte, onlar arasındaki konvansiyonel bağlantıya dair bellek kayıtlarımıza atfettiğimiz sözcüklerden uzaklaşarak okumanın dışına çıkmaya çalışırız. Sözcüklerden, meydana getirdikleri daha geniş sözel bir kalıbın anlamını çıkarmaya çalıştı̆̆ımız diğer yön ise içe doğrudur ve merkezcildir." (ss. 100-101). Edebi eserlerde çeşitli bakış açılarıyla incelenen sembollerin önemli özelliklerinden biri de insanın ruhsal gelişimine ve benliğini keşfediş sürecine katkısıdır. Okur karakterler, mekân ve eserin genel yapısına 
dair yorumlanabilecek ve ilgisini çekebilecek bir ögeyle karşılaşması sonucu etkileşime, düşünme ve anlamlandırma çabasına girebilir. Anlamlandırma isteği etkileşim sebebiyle önemli sembolik bir karşılaşmayı doğurur (May, 2013, ss. 102-103). Bu karşılaşma da sembollerin yorumlanmasında okuyucunun zihninde anlam bütünlügünün oluşmasını sağlar. Okur metinde geçen olayları kendi vizyonu çerçevesinde yorumlar ve ihtiyacı olanı alır.

\section{Dünyanın boğulmuş en güzel adamı adlı öyküde sembollerin hayatın anlamı üzerinden yorumlanması}

García Márquez, öykü yazım tarzında hem içsel deneyimlerini hem de dış çevre algılamasını başarılı bir şekilde okura yansıtmıştır. Yazarın evreni çeşitli renklerden oluşan bir tablo gibidir. Renk uyumluluğu gözetmeksizin her rengi kendi dinamikleri el verdiğince yan yana kullanır. Uyumsuzluğun alışılmadık dengesini yakalamayı başaran yazar sayesinde metinlerin içine çekilen okur, âdeta sihirli bir aynadan içeriye doğru García Márquez'in dünyasına adım atar. İncelemesi yapılan bu öyküde de, bireyin yaşam döngüsündeki gariplikleri ve olağanüstülükleri etkileyici bir dille sunar. García Márquez, İyi Kalpli Eréndira adı altında yazdığı ve Büyülü Gerçekçilik akımının yansımalarının da hissedildiği öyküleri "1960'lı yılların başında Meksika'da başlamışsa da büyük bölümünü 1960'lı yılların sonu ve 1970'lerin başında Barcelona'da kaleme almıştı" (Martin, 2017, s. 97). Kitapta yer alan Dünyanın Boğulmuş En Güzel Adamı adlı öykü García Márquez'in ilgi çekici ve öne çıkan öykülerindendir. “Öyküde yer değiştiren bakış açıları; gizem, keşif, bilgi ve sonunda bir efsanenin doğuşunun oluşturduğu genel halkaya uygun düşer" (Bell-Villada, 2010, s. 197). Öyküde toplamda yirmi evden oluşan, Karayipler'de issız bir alanda konumlanan köyde, çocuklar tarafından deniz kıyısında bulunan erkek cesedinin tüm köy halkının yaşamına etkisi aktarılmaktadır. Denizden kıyıya doğru yaklaşmakta olan cismi öncelikle düşman gemisi zanneden çocuklar cesedin kıyıya vurmasıyla onun bir balina veya herhangi bir deniz canlısı olabileceğini düşünmüşler, fakat cismin üzerindeki yosunları ve deniz artıklarını kaldırdıklarında onun bir erkek bedeni olduğunu fark etmişlerdi (G. Márquez, 2016, s. 43). Su deniz ve kavramı öykü boyunca sembolik bağlamda ağırlı̆̆ını hissettirdiğinden dolayı çözümlenmesi gereken ilk sembollerdendir. Matricon (2015) pek çok anlatıya, efsaneye ve öyküye konu olan suyun görkemini ve önemini şu sözleriyle dile getirir: "Suya her yerde rastlarız ve onun büyüleyici özellikleri kendini bize sonsuz biçimlerde gösterir. Bu büyüleyiciliğin fiziksel-kimyasal açıklaması son derece basittir. Başka elementlerle birleşen, onlardan ayrışan, maddenin üç haline-katı, sıvı ve gaz-çevrimsel olarak dönüşen Dünya'mızın suyu yaşamsal özelliktedir" (s. 11). Hayatın kaynağı veya yaşamın özü olarak da tanımlanan su kavramının mitolojideki yansımasını Gezgin (2016) şu sözleriyle dile getirir:

"Su yaşamdır, yaşamın kaynağıdır, hayat veren, can verendir; ancak su aynı zamanda yıkan, yok eden, boğan ve cana kıyan ezici bir güçtür. Su daima akışkandır, kendi içinde bir döngüye sahiptir; yuttuğu her şeyi bir gün mutlaka verir, ancak verdiği 
şeyleri de geri alır. Mitoslarda yaşam sudan doğmuştur dolayısıyla su insanın ilk kutsallarından birisidir" (s. 8).

$\mathrm{Su}$ alma-verme dengesine sahiptir. Böylelikle hem bereketin anahtarıdır hem de vadesini dolduranı geri alan bir bütünlüğe sahiptir. Öyküde geçen suyun bir parçası olan deniz de önemli simgesel bir rol üstlenmektedir. Farklı kültürel ve evrensel kodları içinde barındıran deniz kavramı macera, gizem ve tehlikeyle beraber anılır. Dünya mitolojisinde okyanuslarda denizlerde ve nehirlerde tanrı ve tanrıçaların sözü geçer. Bu nedenle deniz kutsaldır. Yunan mitolojisinde Poseidon adıyla bilinen deniz tanrıs1, Sirenler, Triton gibi birçok mitolojik varlık hikâyelere konu olmuştur (Dell, 2014, s. 102). Bu eksende yorumlandığında mitolojik dünyanın oluşmasında önlemli bir yere sahip olan MÖ. 800-700 arası yaşadığı düşünülen Homeros'un İlyada ve Odysseia destanları Batı dünyasının ilk yazılı eserleri olarak kabul edildiğini unutmamak gerekir. Bu destanlarda anlatılanlar günümüzde çeşitli eserlere ilham kaynağı olmuştur (Daniels, 2014, s. 128). Homeros'un destanlarda aktardıkları pek çok mitolojik kahramana can vermiş, okuyucuyu gerçeküstü dünyayla tanıştırmış ve birçok yazarın eserlerini oluşturmasında katkıda bulunmuştur. Semboller ve mitoloji arasındaki bağ kolektif bilincin gelişmesinde önemli bir rol oynar. Yüzyıllardır insanoğlunun bilincinde olumlu veya olumsuz kodlarla biriken semboller, farklı bakış açıları eşliğinde edebiyat eserlerinde değerlendirilmeye çalışıldığında, okuyucuda anlam arayışının sorgulamasını sağlar. García Pérez (2010) dünyada birçok yeri gezmiş ve farklı olayları hem yazar hem de gazeteci kimliğiyle yorumlayan García Márquez’in eserlerinde mitolojiden yansımaların görülmesinin ve bu mitolojik sembolleri tahlil etmenin mümkün olduğunu belirtir (ss. 233-257). Öyküde deniz kıyısında bulunan cesetle oynayan çocukları fark eden köyün erkekleri, cesedi incelemeye başlayınca görünüşünden dolayı onun ne kadar da büyük, iriyarı ve güçlü bir erkek olduğunu fark ederler. Cesedin boyutları şu şekilde dile getirilir:

"Onu en yakındaki eve götürmek üzere yüklenen erkekler, bildikleri bütün ölülerden daha ağır, neredeyse bir at kadar ağır olduğunu fark ettiler ve belki de denizde fazlasıyla uzun bir zaman sürüklenip durduğundan sular kemiklerinin içine dolmuştur, dediler kendi kendilerine. Onu yere uzattıklarında herkesten daha iriyarı olduğunu gördüler, evin içine zorlukla sığabiliyordu, ama belki de ölümden sonra da büyümeye devam etme yeteneği bazı boğulan kimselerin doğasında vardır, diye düşündüler” (G. Márquez, 2016, s. 43).

Denizden gelen ölü bir bedenin büyüklüğü, güzelliği ve deniz kavramının işlevselliği de göz önünde bulundurulduğunda denizden gelenin olağanüstü veya insanüstü özelliklere sahip bir varlığı sembolize ettiği düşünülebilir. García Márquez'in mitoloji ve destanlardan da etkilendiği düşünülürse, hem tanrısal bir varlığı ve kutsallığı hem de gizem ve tehlikeyi sembolize etmesi bakımından Homeros'un Odysseus'la ilişkilendirilmesi muhtemeldir. Felten (1986) Odysseia'nın altıncı bölümünde Odysseus'un denizin kirini üstünden atmak için suyla bedenini temizlemesinin ve bu halinin etraftaki insanlar tarafından hayranlıkla izlenmesinin öyküyle benzerlik gösterdiğini belirtir (s. 537). 
Erkek bedeninin ölü olmasına rağmen büyüklüğünden ve güzelliğinden bir şey kaybetmemesi köy halkını derinden etkilemiş, ölü adama karşı hayranlıkla beraber merak uyandırmıştır. Bu noktada güzellik kavramına kısaca göz atmak yerinde olacaktır. Minor (2017) İskoç düşünür Hume’un güzellik kavramından şu şekilde bahseder: “Güzellik bir nesneye içkin veya nesneye özgü bir şey değildir. Güzellik kendi başına şeylerde var olan bir nitelik değildir: Sadece şeyleri düşünen zihinde var olan bir şeydir ve her zihin farklı bir güzellik algılar, der" (s. 128). Hume’un önerdiği bu yaklaşım sonucunda ölü adamın güzelliği köyün kadınlarının ona atfettiği sembol olarak yorumlanabilir. Maglia (2002) ise boğulmuş adamın güzelliğini Platon'un güzellik kavramıyla etkileşimin bir sonucu olarak yorumlamıştır. Platon'a göre güzel iyi, doğru ve faydalıdır; Kalokagathia'dır (para. 4).

Boğulmuş adamın güzelliği; tanrısallığı ve ulaşılmazlığı çağrıştırmaktadır. Yirmi kadar evden meydana gelen, hayatlarında boğulmuş adamla karşılaşmalarına kadar kayda değer bir yenilik bulunmayan, 1ssızlık ve amaçsızlık içinde barınmaya çalışan köy halkı bu grotesk durum karşısında hayatlarını yeniden sorgulamaya başlamışlardır. Denizden gelenin bilinmezliği, bilinmezliğin büyüsü ilk başta kadınları etkisi altına almıştır. Boğulmuş adamı üzerindeki yosunlardan ve bitkilerden temizlemişler, onu arındırdıktan sonra fiziksel heybetinin etkisine kapılmışlardır. Ölü adamın fiziksel güzelliği öyküde şu şekilde aktarılır: "Ama onu temizlemeyi bitirdiklerinde ne tür bir adam olduğunun farkına varabilmişler, işte o zaman nefesleri kesilmişti. Sadece o zamana kadar gördüklerinin içinde en uzun boylusu, en güçlü kuvvetlisi, en erkekçe ve en iyi giyim kuşamlısı olmakla kalmıyordu, aynı zamanda onu seyrettikleri sırada hayallerine de sığmıyordu" (G. Márquez, 2016, s. 44). İlerleyen sürede kadınların boğulmuş adama karşı duydukları hayranlık şu sözlerle devam eder:

"Bu harikulade adam bu köyde yaşamış olsayd1, evinin kapıları daha geniş, damı daha yüksek, zemini daha sağlam olurdu, yatağı demir perçinli sağlam keresteden yapılmış, karısı da köyün en mutlu kadını olurdu, diye düşünüyorlardı. Öylesine otorite sahibi olurdu ki, sadece adlarıyla çağırmakla balıkları denizden çıkarabilir, işine öylesine dört elle sarılırdı ki en kuru taşların arasından pınarlar fışkırmasını sağlayabilir, kayalıkların içine çiçekler dikebilirdi, diye düşünüyorlardı” (G. Márquez, 2016, s. 45).

Boğulmuş adama duyulan abartı derecesindeki hayranlık ve sevgi köy halkının hayatlarının ne denli sıkıcı ve rutine dayalı ilerlediğini okura hissettirir. Bu sembolik karşılaşma sayesinde köy halkı sıradanlığın kırılma noktasını keşfeder ve yaşamın farkına varmaya başlar. Ölü adam üzerinden inşa edilen imgesellik köy halkını değiştiren ve dönüştüren en önemli unsurdur. İlerleyen zaman içerisinde köyün kadınları boğulmuş adamı gitgide benimsemişler, köyün en yaşlı kadını boğulmuş adamın adının Esteban olması gerektiğini düşünürken köyün en geç kadını da adının Lautaro olmasını istemiştir. Öyküde bu durumdan şu şekilde bahsedilir:

"Bu hayal âleminde dolanıp dururlarken, kadınların içinde en yaşlısı ve en yaşlı olduğu için de boğulmuş adamı tutkudan çok acıma duygusuyla seyretmiş olanı, içini 
çekerek şöyle dedi: 'Yüzüne bakınca, adı Esteban'mış gibi geliyor'. Doğruydu da. Adının ondan başka bir şey olamayacağını anlamak için kadınların çoğunun ona bir kez daha bakmaları yeterli olmuştu. En genç oldukları için en inatçı olanlar, elbiselerini giydirip ayağında rugan ayakkabılarla çiçekler arasında yatırdıklarında adının Lautaro olabileceği hayalinden vazgeçemiyorlard1. Ama bu boş bir hayal olmuştu” (G. Márquez, 2016, s. 46).

Bu noktada García Márquez’in Esteban ve Lautaro adlarıyla neyi sembolize etmek istediği incelenmelidir. Esteban ismi Yunancadan Stephanos isminden gelir. Stephanos; miğfer, taç, çelenk, görkem ve zafer anlamına gelmektedir (Maglia, 2002, para. 5). Bu durum yazarın Esteban'1 öyküde yücelterek sunduğunun bir göstergesi sayılabilir. Esteban için bir başka önerme de Esteban'ın adının taşlanarak öldürülen ve Hıristiyanlıkta ilk şehitlerinden Aziz Stefan (Esteban)'dan geldiği yönündedir. Lautaro ise Şili'yi istila etmeye çalışan İspanyollara karşı Aracua Ayaklanmasının başına geçmiş ve ulusal bir simge olmuştur (Felten, 1986, s. 530; Maglia, 2002, para. 7-8; Bell-Villada, 2010, s.196). Lautaro savaşı, adrenalini; Esteban ise fedakârlığı ve kutsallığ sembolize eder. Esteban köyün değişimi ve yaşayanların hayat amaçlarını bulmaları için hem bir rehber hem de kendini feda eden bir sembol olarak yorumlanabilir. Kadınların ve erkeklerin Esteban'1 sahiplenmesi köydeki dönüşümü tetikler. Köyün erkekleri Esteban'ın yakınlarında bulunan köylerden olmadığı haberini getirdiklerinde kadınların Tanrı'ya şükredip artık Esteban'ın onlara ait olduğunu kesinleştirmeleri erkekler tarafından yadırganmıştır (G. Márquez, 2016, s. 47). Kadınların Esteban'a duydukları hayranlığı anlayamayan köyün erkekleri Esteban'1n yüzünü görür görmez fikirlerini değiştirmişler, onun heybetine ve güzelliğine hayran kalmışlardı. Kadınlar Esteban'ın tırnaklarını kesiyor, onun için pantolon ve gömlek dikiyor ve onunla ilgili hayaller kuruyorlardı. Esteban'1 benimsedikçe onun güzelliği ve heybeti köy sakinlerinin kendi içlerine dönmelerini sağlamıştır. Ölünün hem kadınlar hem de erkekler için çok güzel olarak değerlendirilmesi, Esteban'1 muhafaza etme güdüsünü ortaya çıkarmaktadır. Esteban'a baktıkça hem kendilerine hem de diş çevrelerine, yaşam alanlara ve diğer insanlara aynı özeni göstermeye başlamışlar, kendilerinin farkına varmışlar böylelikle hayat amacı kazanmışlardır. Çalışmanın giriş bölümünde belirtildiği üzere Frankl ve Adler'in de dediği gibi kişi hayatın amacı ve anlamı için bir faaliyete, eyleme bir başlangıca ihtiyacı vardır. Öykünün sonunda Esteban için hazırlanan cenaze töreni hayat ve ölüm üzerinden değerlendirildiğinde önemli bir semboldür. Esteban'la karşılaşma anına kadar birbirleriyle iletişim içinde olmayan köy sakinleri cenaze vasıtasıyla birbirilerinin farkına varmışlardır. Bu durum eserde şu şekilde yorumlanmıştır:

“İşte böylece, terk edilmiş bir boğulmuş adam için yapılabilecek en görkemli cenaze töreni yapılmış oldu. Komşu köylerden çiçek bulup getirmeye giden bazı kadınlar, anlattıklarına inanmayan başkalarıyla birlikte geri dönmüşler, bunlar da ölüyü gördükleri zaman daha fazla çiçek getirmeye gitmişler (...) Son dakikada onu denize öksüz olarak geri vermek yüreklerini sızlatınca, en iyilerinin arasından ona bir anne ile bir baba seçmişler, başkaları da ona kardeş, amca, dayı, yeğen olmuşlar, böylelikle tüm köy sakinleri, onun aracılığıyla birbirleri akrabalık kurmuşlardı” (G. Márquez, 2016, s. 47). 
Bir başka cümle de ise bahsi geçen süreç şu şekilde aktarılır: "Cenazeyi kayalıkların dimdik yokuşundan omuzlar üzerinde çıkarma ayrıcalığını tartıştıkları sırada, erkeklerle kadınlar, boğulmuş adamlarının debdebesi ve güzelliğine karşılık köydeki sokaklarının ne kadar ıssız, avlularının çorak, hayallerinse güdük olduğunun ilk kez farkına varmışlardı (G. Márquez, 2016, s. 49). Bu farkındalığın ardından içlerindeki boşlukla yüzleşmişler, bu durumdan kurtuluşu Esteban'ın anısını yaşatarak başarmak istemişlerdir. Sembolik çerçevede Esteban'ın ortaya çıkardığ 1 değişim eserde şu şekilde dile getirilir: "Esteban'ın anısını sonsuza dek sürdürmek için evlerin cephelerini canlı renklere boyayacaklar, taşların arasını kazıp pınarlar bulacaklar, yalıyara çiçekler dikecekler, böylelikle gelecek yıllarda şafak vakti geçecek büyük vapurların yolcuları açık denizde bahçelerden buram buram gelen bir çiçek kokusuyla uyanacaklar” (G. Márquez, 2016, s. 50). Öykünün son cümlelerinde köyün bu yaşananlardan sonra artık Esteban'ın köyü olduğunu ve güneşin daima parlayacağı belirtilmiştir (G. Márquez, 2016, s. 50).

Esteban, hayata dair herhangi bir amacı olmayan, anlam karmaşası yaşayan köy halkına ilham kaynağı olmuş ve hayattan umudu kesmiş bir köyü hayata döndürmüştür. Boğulmuş bir adamın fiziksel anlamda yaşayan ama ruhsal bağlamda ölü olarak yorumlanan köye ve köy halkına yaşam kaynağı olması yazarın ironik bakış açısının simgesel yansıması olabilir. García Márquez köye ruhsal anlamda nefes alması ve köyün kendini gerçekleştirmesi için boğulmuş bir adamı rehber olarak göndermiştir. Ölüm ve yaşam arasındaki iki zıt noktayı adeta birbirine bağlamış, böylelikle amaçsızlığın ortadan kalkmasını sağlamıştır.

\section{Sonuç}

Nitelikli edebî eserler, okuyucunun dünyayı derin bir bakış açıyla algılamasını sağlar. Hayata dair anlam kaygısını dindirme görevini üstlenir. Okuyucunun farkındalık kazanmasına yardımcı olur. Böylelikle eserlerde geçen olaylar ve karakterler aracılığıyla okuyucu kendisiyle yüzleşir, hayatın anlamı üzerine düşünür. Farklı olanı yargılamaz, olduğu gibi kabul eder. García Márquez'in eserleri okuru garip ve alışılmışın dışındaki kurgusuyla hem büyüleyen hem de okurun bu sihirli ve grotesk akışı normal karşılamasını sağlayan bir bütünlüğe sahiptir. Kendisiyle karşılaşmak ve kendini tanımak isteyen okur için metinler sembollerle dolu bir dünya sunar. Burada dikkat edilmesi gereken bir diğer nokta da, bahsedilen niteliğe sahip ve evrensellik mertebesine ulaşan eserleri yaratan yazarların önemidir. Doğaüstü olayların olası karşılandığı Büyülü Gerçekçilik akımının mimarlarından García Márquez evrensel nitelikte eserler üretmiş ve onun sayesinde birçok okuyucu acayip ve alışılmadık olaylardan doğan sembollerle dolu eserleri olağan deneyimlemiştir. Bu çalışmada Dünyanın Boğulmuş En Güzel Adamı adlı öykünün semboller üzerinden hayatın anlamına ve amacına dair bir değerlendirmesi yapılmaya çalışılmıştır. Öncelikle öyküde hayatın anlamının yorumlanmasına dair önemli sembollerden biri su ve deniz kavramları tespit edilmiştir. Öyküde ölü adamı veren ve alan deniz gizem ve macerayı temsil etmektedir. Ölü adamın isimlendirilmesi ve bu sü- 
reçte ona Esteban ve Lautaro isimlerinin düşünülmesi de öyküde öne çıkan sembollerdendir. Ölü adama verilen adın Esteban olarak kararlaştırılması Esteban'ın halkı hangi özellikleriyle etkilediğinin göstergesi olarak yorumlanabilir. Esteban'ın iri cüssesine ve güzelliğine hayran kalan köyün kadınları onu ilk gördükleri anda köyden biri olarak benimsemişler ve ona hayranlıkla bakmışlardır. Köydeki kadınların hayranlık ve güzellik algısı, Esteban'ın ulaşılmazlığı ve tanrısallığı birer semboldür. Esteban'ı korumak ve muhafaza etmek isteyen halk bu sayede kendi hayatlarının anlamsız ve sönük olduğunu fark eder. Deniz kıyısında bulunan ölü erkek bedeninin köyü hayata bağlaması ve onlara ilham kaynağı olması, yazarın ironik bakış açısı olarak yorumlanabilir. Köyün kendisini gerçekleştirmesi için Esteban'dan güç alması ve onun sayesinde önce kendisinin sonra da çevrenin farkına varması öyküdeki önemli izleklerdendir. Fiziksel anlamda yaşayan, fakat ruhen kendini bulamayan bir köyü uyandırmak ve köy sakinlerinin hayata adım atmasını sağlamak için yazarın boğulmuş, ölü bir adamı göndermesi oldukça ilgi çekici ve önemli bir detaydır.

Her insanın içinde sahip olduğu yaşamsal bir enerji vardır. Bu enerji insanın özü olarak da tanımlanabilir. İnsan herhangi bir olayla karşılaştığında yaşamsal enerji yükselerek ortaya çıkar. Öyküde Esteban, köyün yaşam enerjisini ortaya çıkaran bir sembol veya tetikleyici bir detaydır. Esteban ve köy halkının karşılaması, ölü olan Esteban'ın köye ayna olması, kendi içlerindeki ruhsal çöküşü Esteban'ın bedeni üzerinden deneyimleyen köy halkının aynı şekilde Esteban'a yüklediği güzellik, hayranlık ve güçlülük gibi göreceli kavramların kendi üzerindeki yansımalarını fark etmesi öykünün dikkat edilmesi gereken unsurlarındandır. Belki de yazarın okuyucuya sezdirmek istediği Esteban ve öyküdeki diğer öğeler gibi dışarıdan kişiye etki eden çevresel ve diş faktörlerin kişiyi sadece harekete geçirmeyi sağladığıdır. Değişim ve dönüşüm insanın kendi içinde başlar ve kendini gerçekleştirmek için yol alır. Bu durumda kişi ne kadar birine ya da bir şeye anlam yüklese de kendini tek başına gerçekleştirecektir. Dönüşüm sürecinde etkileşim içinde olduğu her şey kişiye rehberlik etmesine rağmen, kendini gerçekleştirme yolculuğunda en önemli rehberin kendisi olduğunu anlayabilen kişinin ortaya koydukları ve yaptıklarıyla da hayatı manen zenginleşecek ve anlam kazanacaktır.

\section{Kaynaklar}

Adler, A. (2016) Yaşamın anlam ve amacı. (Çev. K. Şipal) İstanbul: Say.

Aytaç, G. (2009) Genel edebiyat bilimi. İstanbul: Say.

Bell-Villada, G. H. (2011) Bir söz büyücüsü: García Márquez. (Çev. İ. Özdemir) İstanbul: Kırmızı Kedi.

Bucay, J. (2010) İleri doğru atılan yirmi adım. (Çev. P. Savaş) İstanbul: Butik. Daniels, M. (2014) Bir nefeste dünya mitolojisi. (Çev. P. Üstel) İstanbul: Maya.

Dell, C. (2014) Mitoloji-Hayali dünyalara eksiksiz rehber. (Çev. N. Elhüseyni) İstanbul: Yap1 Kredi. 
Felten, H. (1986) El ahogado más hermoso del mundo: lectura plural de un texto de García Márquez. In: Actas del IX Congreso de la Asociación Internacional de Hispanistas, 535-542. Frankfurt am Main, Germany: Verveiert, 1989. Erişim adresi: https://cvc.cervantes.es/literatura/aih/pdf/09/aih_09_2_061.pdf Erişim tarihi: 20.12. 2017

Frankl, V. E. (2016) Hayatın Anlamı ve Psikoterapi. (Çev. V. Ataman) İstanbul: Say.

Fromm, E. (2015) Rüyalar, masallar, mitler. (Çev. A. Arıtan ve K. H. Ökten) İstanbul: Say.

Frye, N. (2015) Eleştirinin anatomisi. (H. Koçak, Çev) İstanbul: Ayrıntı.

García Márquez, G. (2016) Iyi kalpli Eréndira. (Çev. İ. Kut) İstanbul: Can Sanat.

García Perez, D. (2010) Tres mitos griegos en la narrativa de Gabriel García Márquez. Nova Tellus, 28, (2). 233-257.

Gezgin, D. (2016) Su mitosları. İstanbul: Sel.

Jung, C. J. (2016) Insan ve sembolleri. (Çev.H. M. İlgün) İstanbul: Kabalcı.

Maglia, G. (2002) Una lectura intertextual de“el ahogado más hermoso del mundo" de Gabriel García Márquez. Revista de la Facultad de Artes Y Humanidades, 15.

Manguel, A. (2017) Okumalar okuması. (Çev. S. Okyay) İstanbul: Yapı Kredi.

Martin, G. (2017) Gabriel García Márquez'e giriş. (Çev. E. İmre) İstanbul Can Sanat.

Matricon, J. (2015) Yaşasın su. (Çev. A. Derman) İstanbul: Yapı Kredi.

May, R. (2013) Yaratma cesareti. (Çev. A. Oysal) İstanbul: Metis.

Minor, V. H. (2017) Sanat tarihinin tarihi. (Çev. C. Soydemir) İstanbul: Koç Üniversitesi. 